\title{
The Tricarboxylic Acid Cycle in Dictyostelium discoideum
}

\author{
METABOLITE CONCENTRATIONS, OXYGEN UPTAKE AND ${ }^{14} \mathrm{C}$-LABELLED AMINO \\ ACID LABELLING PATTERNS \\ By Patrick J. KELLY, Joanne K. KELLEHER and Barbara E. WRIGHT \\ Department of Developmental Biology, Boston Biomedical Research Institute, 20 Staniford Street, Boston, \\ MA 02114, U.S.A.
}

(Received 23 April 1979)

\begin{abstract}
Some aspects of tricarboxylic acid-cycle activity during differentiation and aging in Dictyostelium discoideum were examined. The concentrations of glutamate, aspartate, alanine, citrate, 2-oxoglutarate, succinate, fumarate, malate, oxaloacetate, pyruvate and acetyl-CoA were determined at four stages over the course of differentiation. The rate of $\mathrm{O}_{2}$ utilization was also determined over differentiation. In addition, experiments are described in which the specific radioactivities of citrate, 2-oxoglutarate, succinate, fumarate and malate were determined during a $30 \mathrm{~min}$ labelling of cells from the preculmination stage of development with $\left[{ }^{14} \mathrm{C}\right]$ glutamate, $\left[{ }^{14} \mathrm{C}\right]$ aspartate or $\left[{ }^{14} \mathrm{C}\right]$ alanine. A similar experiment was also performed with cells from the aggregation stage of development using $\left[{ }^{14} \mathrm{C}\right]$ glutamate.
\end{abstract}

The life-cycle of the amoeba Dictyostelium discoideum is characterized by a free-living vegetative phase in the presence of an adequate food source, and, under starvation conditions, a phase in which the amoebae aggregate, age and differentiate into one of two cell types. Differentiation is completed with the formation of a fruiting body composed of a cellulose stalk supporting a mass of spore cells and requires, under laboratory conditions, about $24 \mathrm{~h}$. The stalk cells die and the spore cells enter into a state of dormancy.

In common with many other systems (Wright, 1967) differentiation in Dictyostelium is dependent on endogenous metabolism as a source of carbon and energy. Metabolically the system is closed. For example, differentiation in Dictyostelium results in the catabolism of about $50 \%$ of the cellular protein (White \& Sussman, 1961; Wright \& Anderson, 1960). It has been suggested that this protein serves mainly as substrate for the tricarboxylic acid cycle and energy production (Wright, 1964). This suggestion is supported by the finding that the rate of gluconeogenesis from $\left[{ }^{14} \mathrm{C}\right]$ aspartate, estimated by the entry of label into trehalose and cellulose, is low (Cleland $\&$ Coe, 1964). Hence the catabolized protein does not appear to be directed towards the synthesis of glucose.

The conversion of protein to tricarboxylic acidcycle intermediates and their subsequent oxidation must begin with proteolysis, and several enzymes (acid proteinase and aminopeptidase) that may play a role in this process have been isolated from Dictyostelium (Firtel \& Brackenbury, 1972; Sussman \& Sussman, 1969; Weiner \& Ashworth, 1970; Gustafson
$\&$ Thon, 1979). In addition, various enzymes involved in the conversion of the resultant amino acids to cycle intermediates have been examined (Brühmüller \& Wright, 1963; Firtel \& Brackenbury, 1972; Langridge et al., 1977; Pong \& Loomis, 1971a,b). Very little is known about the oxidative segment of this process. Citrate synthase (EC 4.1.3.7) has been partially purified and characterized (Porter \& Wright, 1977), and the respiratory chain of late-exponentialphase amoebae has been examined and its components shown to be similar to other eukaryotic systems (Erikson \& Ashworth, 1969). In addition, several enzymes associated with the chain have been studied (Takeuchi, 1960).

Gregg (1950) and Liddel \& Wright (1961) have examined the uptake of $\mathrm{O}_{2}$ by Dictyostelium during differentiation, and the latter workers reported a decrease in the $Q_{\mathrm{O}_{2}}(\mu \mathrm{l} / \mathrm{min}$ per mg dry wt.) to $25 \%$ of the initial value as the organism progressed from the amoeba to sorocarp stages. In addition, changes in mitochondrial structure have been observed during differentiation (Ashworth et al., 1969; George et al., 1972).

Hence it is apparent that differentiation is accompanied by alterations in the oxidative metabolism of this organism, correlated with changes in mitochondrial structure, the activity of several enzymes associated with the respiratory chain, and the rate of $\mathrm{O}_{2}$ uptake. Lloyd (1970) has pointed out 'the study of processes of cellular differentiation involved in the life-cycle of many eukaryotic microorganisms constitutes a major field of biochemical activity. Yet with few exceptions, there has been little attempt to investigate the extent of changes in mitochondrial 
composition and activity or the control mechanisms implicated in the striking variations in respiration observed at the whole cell level.'

In Dictyostelium the tricarboxylic acid cycle is responsible for the oxidation of catabolized protein and hence constitutes an essential part of the process of differentiation. The present paper describes some of the tricarboxylic acid-cycle characteristics at the preculmination and aggregation stages of development.

\section{Materials}

\section{Organism}

D. discoideum (strain NC-4, A.T.C.C. 24697) was grown on nutrient-agar sheets in association with Escherichia coli as previously described (Marshall et al., 1970). Amoebae were harvested and washed free of bacteria by differential centrifugation at $4^{\circ} \mathrm{C}$. Cell suspensions were washed 3 times and suspended in distilled water before being spread on $2 \%$ agar containing $10 \mathrm{~mm}$-potassium phosphate buffer (pH6.5) and 1 mM-EDTA.

\section{Radionuclides}

[U- ${ }^{14} \mathrm{C}$ ]Glutamic acid $(244 \mathrm{mCi} / \mathrm{mmol}),\left[\mathrm{U}-{ }^{14} \mathrm{C}\right]-$ aspartic acid $(192 \mathrm{mCi} / \mathrm{mmol}),\left[\mathrm{U}-{ }^{14} \mathrm{C}\right]$ alanine $(154 \mathrm{mCi} / \mathrm{mmol}),\left[1,5-{ }^{14} \mathrm{C}\right] \mathrm{citric}$ acid $(8.2 \mathrm{mCi} / \mathrm{mmol})$, 2-oxo[U-14 C]glutaric acid $(254 \mathrm{mCi} / \mathrm{mmol})$ and $\left[1,4-{ }^{14} \mathrm{C}\right]$ succinic acid $(20 \mathrm{mCi} / \mathrm{mmol})$ were obtained from New England Nuclear, and $\left[2-{ }^{14} \mathrm{C}\right] \mathrm{malic}$ acid $(49 \mathrm{mCi} / \mathrm{mmol})$ and $\left[1-{ }^{14} \mathrm{C}\right]$ acetyl-CoA $(60 \mathrm{mCi} / \mathrm{mmol}$ were obtained from Amersham/Searle.

\section{Chemicals}

Glutamic acid, aspartic acid, citric acid, succinic acid, fumaric acid, malic acid, pyruvic acid and alanine were obtained from Sigma Chemical Co. Acetyl-CoA and NADH were obtained from Boehringer/Mannheim.

\section{Enzymes}

Citrate lyase (EC 4.1.3.6), succinic thiokinase (EC 6.2.1.4), pyruvate kinase (EC 2.7.1.40), lactate dehydrogenase (EC 1.1.1.27), fumarase (EC 4.2.1.2), glutamate dehydrogenase (EC 1.4.1.3) and malate dehydrogenase (EC 1.1.1.37) were obtained from Sigma Chemical Co. Citrate synthase (EC 4.1.3.7) and aspartate aminotransferase(EC2.6.1.1) were from Boehringer/Mannheim.

\section{Methods}

\section{Metabolite assays}

Alanine, glutamate, aspartate, citrate, 2-oxoglutarate, succinate, malate, fumarate and pyruvate were all assayed by published methods (Bergmeyer,
1976) either spectrophotometrically or fluorimetrically. Acetyl-CoA was measured radiochemically by the method of Schoner \& Seubert (1970). The reaction mixture contained $\left[4-{ }^{14} \mathrm{C}\right]$ aspartate $(0.1 \mu \mathrm{Ci}), 2$ oxoglutarate $(1 \mu \mathrm{mol})$, aspartate aminotransferase (5units), citrate synthase (5units) and Tris/ $\mathrm{HCl}$ buffer $(5 \mu \mathrm{mol}, \mathrm{pH} 7.5)$ in $200 \mu \mathrm{l}$. One unit of enzyme is that amount that converts $1 \mu \mathrm{mol}$ of substrate $/ \mathrm{min}$. The reaction mixtures were covered and incubated at room temperature for $15 \mathrm{~min}$ before the addition of sample (0-5 nmol of acetyl-CoA). The reaction mixtures were again incubated at room temperature for $15 \mathrm{~min}$, carrier citrate $(20 \mu \mathrm{mol})$ was added, and the assay mixtures were heated at $100^{\circ} \mathrm{C}$ for $1 \mathrm{~min}$. $\left[{ }^{14} \mathrm{C}\right]$ Citrate was separated from $\left[{ }^{14} \mathrm{C}\right]$ aspartate on Dowex 50 (X12) ion-exchange resin. $\left[{ }^{14} \mathrm{C}\right]$ Aspartate was retained by the column while $\left[{ }^{14} \mathrm{C}\right]$ citrate was eluted from it. Oxaloacetic acid was measured by a modification of the acetyl-CoA assay. The reaction mixture contained $\left[{ }^{14} \mathrm{C}\right]$ acetyl-CoA $(0.05 \mu \mathrm{Ci})$, acetyl-CoA $(2 \mathrm{nmol})$, citrate synthase (5 units), Tris/ $\mathrm{HCl}$ buffer $(10 \mu \mathrm{mol}, \mathrm{pH} 7.5)$ and sample $(0-5 \mathrm{nmol}$ of oxaloacetate) in $0.5 \mathrm{ml}$. The assays were incubated at room temperature for $15 \mathrm{~min}$, heated at $100^{\circ} \mathrm{C}$ for $1 \mathrm{~min}$, and citrate $(20 \mathrm{nmol})$ was added. $\left[{ }^{14} \mathrm{C}\right] \mathrm{Citrate}$ and $\left[{ }^{14} \mathrm{C}\right]$ acetyl-CoA were separated by t.l.c. The chromatogram was developed in a phenol/formic acid/water $(7: 2: 1$, by vol.) system. Standards were chromatographed concurrently and these areas sectioned and counted for radioactivity. Having localized the $\left[{ }^{14} \mathrm{C}\right]$ citrate standard the corresponding areas were excised from the test runs and counted for radioactivity.

The metabolite concentrations were calculated from the known wet weight of the analysis sample, and wet-weight/packed-cell volumes ratios were determined at each stage for each experiment. The packed-cell volumes were corrected for extracellular space (Barravecchio et al., 1969).

Uptake, incorporation and metabolism to $\mathrm{CO}_{2}$ of ${ }^{14} \mathrm{C}$ labelled amino acids

For the uptake experiment, cells were harvested at the preculmination stage of development and suspended in $5 \mathrm{~mm}$-potassium phosphate, $\mathrm{pH}$ 7.0. The suspension contained approx. $50 \mathrm{mg}$ dry wt. $/ \mathrm{ml}$. Portions of the suspension were incubated with carrier-free [U-14 $\mathrm{C}$ ]glutamate $(0.06 \mu \mathrm{Ci}),\left[\mathrm{U}-{ }^{14} \mathrm{C}\right]-$ alanine $(0.09 \mu \mathrm{Ci})$ or $\left[\mathrm{U}-{ }^{14} \mathrm{C}\right.$ ]acetate $(0.2 \mu \mathrm{Ci})$. Samples were removed and centrifuged $(1500 \mathrm{~g} / 2 \mathrm{~min})$. The supernatant was boiled to remove ${ }^{14} \mathrm{CO}_{2}$ and samples were counted for radioactivity.

For the incorporation and ${ }^{14} \mathrm{CO}_{2}$-evolution experiment, cells were harvested at the preculmination stage of development as before. Portions $(2 \mathrm{ml})$ of the suspension were added to vials equipped with a $\mathrm{CO}_{2}$ trap $(14 \mathrm{M}-\mathrm{NaOH} ; 200 \mu \mathrm{l})$, and carrier-free [U-14 $\mathrm{C}$ ]- 
glutamate $(0.02 \mu \mathrm{Ci})$, [U- ${ }^{14} \mathrm{C}$ ]aspartate $(0.02 \mu \mathrm{Ci})$ or [U- ${ }^{14} \mathrm{C}$ ]alanine $(0.2 \mu \mathrm{Ci})$ was added by syringe through a gas-tight stopper. Vials were shaken at room temperature. At various times over $30 \mathrm{~min}$ vials were removed and $2.5 \mathrm{M}-\mathrm{H}_{2} \mathrm{SO}_{4}(200 \mu \mathrm{l})$ was added to the cell suspension, again by syringe. The vials were left on ice for $2 \mathrm{~h}$, and $50 \mu \mathrm{l}$ of the $\mathrm{NaOH}$ trap was counted for radioactivity. Portions $(200 \mu \mathrm{l})$ of the acidified cell suspension were filtered, washed repeatedly with $6 \%(\mathrm{w} / \mathrm{v}) \mathrm{HClO}_{4}$ and counted for radioactivity.

\section{Labelling of tricarboxylic acid-cycle intermediates by ${ }^{14} \mathrm{C}$-labelled amino acids}

Cells were harvested at the preculmination or aggregation stage of development and suspended in $100 \mathrm{ml}$ of phosphate buffer $(5 \mathrm{~mm}, \mathrm{pH} 7.0)$. The suspension contained approx. $50 \mathrm{mg}$ dry wt. $/ \mathrm{ml}$. Carrierfree $\left[\mathrm{U}-{ }^{14} \mathrm{C}\right]$-glutamate, -aspartate or -alanine $(8 \mu \mathrm{Ci})$ was added, and portions $(10 \mathrm{ml})$ were removed over a 30 min period. The samples were frozen in liquid $\mathbf{N}_{2}$, ethanol was added to $75 \%(\mathrm{v} / \mathrm{v})$, and the samples were allowed to thaw. Cell debris was removed $(5000 \mathrm{~g}$, $5 \mathrm{~min}$ ) and $1 \mathrm{vol}$. of water added to the samples, which were then freeze-dried. The freeze-dried material was taken up in $10 \mathrm{ml}$ of water and centrifuged $(5000 \mathrm{~g}$, $5 \mathrm{~min})$. Tricarboxylic acid-cycle intermediates were fractionated on a column of Dowex AGl-1 (X10). The resin was washed with $2 \mathrm{M}-\mathrm{HCl}$ and several volumes of distilled water before being poured into a column $(1 \mathrm{~cm} \times 4 \mathrm{~cm})$. The sample was applied and the column rinsed with $10 \mathrm{ml}$ of distilled water. An $\mathrm{HCl}$ gradient $(0-16 \mathrm{mM}, 500 \mathrm{ml})$ was then applied and fractions $(5.5 \mathrm{ml})$ were collected. Samples were removed from the fractions and counted for radioactivity. With this system alanine did not bind to the column. Glutamate and aspartate were eluted together at a low $\mathrm{HCl}$ concentration, followed by succinate, malate, fumarate, citrate and 2-oxoglutarate. The purity of the various fractions was ascertained by two-dimensional t.l.c. The first and second solvent systems were ether/formic acid/water $(7: 2: 1$, by vol.) and phenol/water/formic acid $(75: 25: 1$, by vol.) respectively. The various fractions were collected, freeze-dried, resuspended in $2 \mathrm{ml}$ of water, counted for radioactivity and assayed. In the $\left[{ }^{14} \mathrm{C}\right]$ glutamatelabelling experiment the extracts were first fractionated on Dowex 50 (X12) resin and then as above in order to remove glutamate. Tricarboxylic acid-cycle intermediates did not bind to the resin. Control experiments were performed in order to investigate the possibility that the experimental conditions used for the labelling studies might lead to a change in the steady-state concentrations of various metabolites. Cells were harvested and suspended as above and samples removed over $30 \mathrm{~min}$ and processed as above but assayed for malate, fumarate, citrate and succinate before fractionation.

\section{$\mathrm{O}_{2}$ uptake}

Cells were harvested and suspended as above. $\mathrm{O}_{2}$ uptake was measured polarographically. Phosphate buffer $(5 \mathrm{~mm}, \mathrm{pH} 7.0 ; 1 \mathrm{ml})$ was allowed to equilibrate to $20^{\circ} \mathrm{C}$ and $50 \mu$ l of cell suspension added.

\section{Results}

The concentrations of various tricarboxylic acidcycle intermediates and related metabolites were determined over the course of differentiation (Table 1). The concentrations differ by several orders of magnitude, with oxaloacetate being the smallest pool and succinate the largest. All the intermediates examined increase in concentration over the course of differentiation, usually between the preculmination and sorocarp stages of development. The final

Table 1. Concentrations of tricarboxylic acid-cycle and related metabolites during differentiation Cells were harvested at the aggregation $(12 \mathrm{~h})$, pseudoplasmodium $(15 \mathrm{~h})$, preculmination $(20 \mathrm{~h})$ and sorocarp $(24 \mathrm{~h})$ stages of development. $\mathrm{HClO}_{4}$ extracts were prepared and the metabolites assayed. The results shown are means \pm S.E.M. for four independent measurements. Concentrations are expressed in terms of packed-cell volume (see the Methods section).

Concentration (mM)

\begin{tabular}{|c|c|c|c|c|c|}
\hline \multirow{2}{*}{ Metabolite } & \multirow[b]{2}{*}{ Stage } & \\
\hline & & Aggregation & Pseudoplasmodium & Preculmination & Sorocarp \\
\hline Alanine & & $0.71 \pm 0.20$ & $0.81 \pm 0.19$ & $0.97 \pm 0.30$ & $2.54 \pm 0.90$ \\
\hline Glutamate & & $0.37 \pm 0.07$ & $0.78 \pm 0.30$ & $1.20 \pm 0.75$ & $2.38 \pm 0.65$ \\
\hline Aspartate & & $0.09 \pm 0.015$ & $0.20 \pm 0.03$ & $0.37 \pm 0.07$ & $1.0 \pm 0.14$ \\
\hline Pyruvate & & $0.06 \pm 0.002$ & $0.05 \pm 0.0025$ & $0.06 \pm 0.005$ & $0.10 \pm 0.0025$ \\
\hline Acetyl-CoA & & $0.009 \pm 0.001$ & $0.012 \pm 0.0015$ & $0.012 \pm 0.001$ & $0.03 \pm 0.002$ \\
\hline Citrate & & $0.017 \pm 0.005$ & $0.03 \pm 0.01$ & $0.06 \pm 0.01$ & $0.37 \pm 0.05$ \\
\hline 2-Oxoglutarate & & $0.005 \pm 0.001$ & $0.010 \pm 0.002$ & $0.010 \pm 0.002$ & $0.018 \pm 0.003$ \\
\hline Succinate & & $1.62 \pm 0.25$ & $1.82 \pm 0.16$ & $1.67 \pm 0.23$ & $2.82 \pm 0.13$ \\
\hline Fumarate & & $0.024 \pm 0.008$ & $0.018 \pm 0.004$ & $0.03 \pm 0.006$ & $0.055 \pm 0.01$ \\
\hline Malate & & $0.15 \pm 0.03$ & $0.21 \pm 0.03$ & $0.28 \pm 0.07$ & $0.46 \pm 0.04$ \\
\hline Oxaloacetate & & $0.002 \pm 0.001$ & $0.001 \pm 0.0003$ & $0.001 \pm 0.0003$ & $0.003 \pm 0.001$ \\
\hline
\end{tabular}


Table 2. $Q_{\mathrm{O}_{2}}$ at various stages of development A portion $(50 \mu \mathrm{l})$ of a cell suspension was added to $1 \mathrm{ml}$ of phosphate buffer $(5 \mathrm{~mm}, \mathrm{pH} 7.0)$, pre-equilibrated to $20^{\circ} \mathrm{C}$, and $\mathrm{O}_{2}$ uptake measured polarographically.

\begin{tabular}{lc}
\multicolumn{1}{c}{ Stage } & $\begin{array}{c}Q_{\mathrm{O}_{2}} \\
(\mu \mathrm{l} / \mathrm{min} \text { per } \\
\mathrm{mg} \text { dry wt. })\end{array}$ \\
Aggregation & 0.29 \\
Pseudoplasmodium & 0.25 \\
Preculmination & 0.16 \\
Sorocarp & 0.17
\end{tabular}

(sorocarp) values represent increases of from 1.5- to 10-fold of the initial (aggregation) values.

The rate of $\mathrm{O}_{2}$ uptake, determined at several stages from aggregation to sorocarp formation, is shown in Table 2 and is essentially in agreement with that determined by Liddel \& Wright (1961) using manometric methods. The rate of $\mathrm{O}_{2}$ uptake decreased by $42 \%$ between aggregation and preculmination and then remained constant until sorocarp formation.

Uptake by the cells of all the amino acids was initially rapid. For glutamate and alanine approx. $25 \%$ was taken up within $5 \mathrm{~min}$, and $43 \%$ of the aspartate was taken up in the same period. The rate of

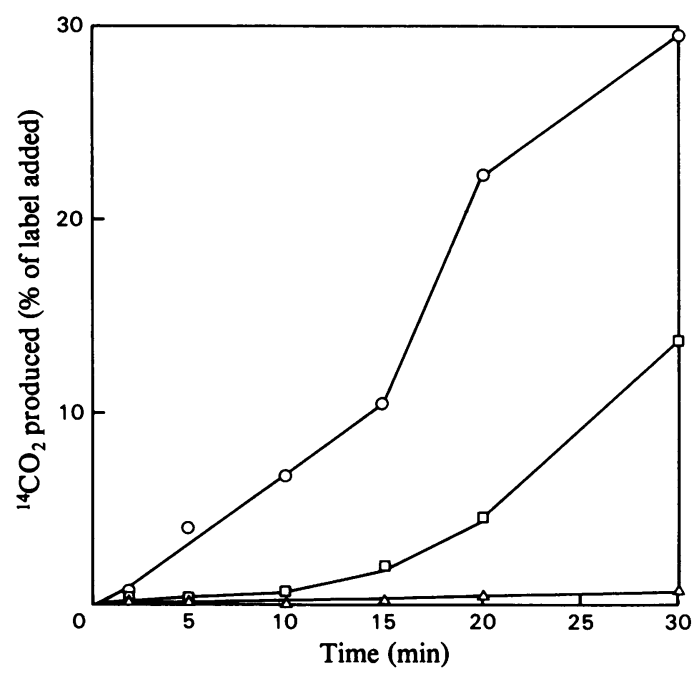

Fig. 1. Conversion of ${ }^{14} \mathrm{C}$-labelled amino acids to $\mathrm{CO}_{2}$ by Dictyostelium

Cells were harvested at the preculmination stage of development, suspended in phosphate buffer $(5 \mathrm{mM}$, pH7.0) and incubated with $\left[{ }^{14} \mathrm{C}\right]$ glutamate $(0)$, $\left[{ }^{14} \mathrm{C}\right]$ aspartate $(\square)$ or $\left[{ }^{14} \mathrm{C}\right]$ alanine $(\Delta)$ in gas-tight vials equipped with a $\mathrm{CO}_{2}$ trap $(14 \mathrm{M}-\mathrm{NaOH} ; 200 \mu \mathrm{l})$. Vials were removed at intervals, $2.5 \mathrm{M}-\mathrm{H}_{2} \mathrm{SO}_{4}(200 \mu \mathrm{l})$ was added by syringe to the suspension, and a portion $(50 \mu \mathrm{l})$ of the trap counted for radioactivity. uptake then decreased for all three, so that, for glutamate and aspartate; only a further $20 \%$ was taken up in the next $40 \mathrm{~min}$. Acetate was taken up by the cells much more rapidly: within $5 \mathrm{~min}, 72 \%$ was removed from the medium.

When the production of ${ }^{14} \mathrm{CO}_{2}$ from ${ }^{14} \mathrm{C}$-labelled amino acids was examined, glutamate was found to be the best substrate, followed by aspartate and alanine. Over a $30 \mathrm{~min}$ experiment $30 \%$ of the $\left[{ }^{14} \mathrm{C}\right]-$ glutamate added to the suspension and $13 \%$ of the $\left[{ }^{14} \mathrm{C}\right]$ aspartate were recovered as $\mathrm{CO}_{2}$, whereas less than $1 \%$ of the $\left[{ }^{14} \mathrm{C}\right]$ alanine added was oxidized (Fig. 1). Glutamate also supports a higher rate of respiration in mitochondria isolated from all stages of differentiation in Dictyostelium (F. DeToma, personal communication). Incorporation of ${ }^{14} \mathrm{C}$ labelled amino acids into $\mathrm{HClO}_{4}$-insoluble material was negligible over $30 \mathrm{~min}$ under these conditions.

The procedure outlined in the Methods section was used to fractionate the tricarboxylic acid-cycle intermediates from cell samples that had been removed at various times from a $\left[{ }^{14} \mathrm{C}\right]$ glutamate incubation. This procedure resulted in the isolation of a crude tricarboxylic acid-cycle-intermediate fraction from which the individual intermediates were then isolated. Fig. 2 shows the conversion of $\left[{ }^{14} \mathrm{C}\right]$ glutamate into this crude fraction: $10 \%$ of the label is converted immediately (10-15s), and a further $20 \%$ is converted at an approximately linear rate over the following $30 \mathrm{~min}$. The specific radioactivities of all the tricarboxylic acid-cycle intermediates examined (Fig. 3) exhibited a rapid initial rise similar to the initial con-

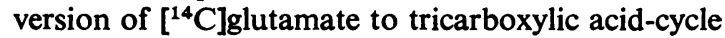
intermediates. Several intermediates (succinate and

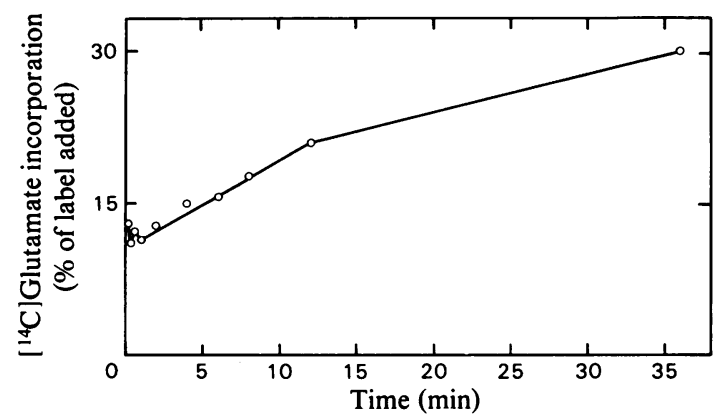

Fig. 2. Incorporation of $\left[{ }^{14} \mathrm{C}\right]$ glutamate into a crude tricarboxylic acid-cycle-intermediate fraction

Cells from the preculmination stage of development were incubated with $\left[{ }^{14} \mathrm{C}\right]$ glutamate. Portions were removed, frozen, extracted with $75 \%$ ethanol and the extracts chromatographed on Dowex 50 (X12) ionexchange resin. $\left[{ }^{14} \mathrm{C}\right]$ Glutamate was bound to the column and tricarboxylic acid-cycle metabolites were eluted. 


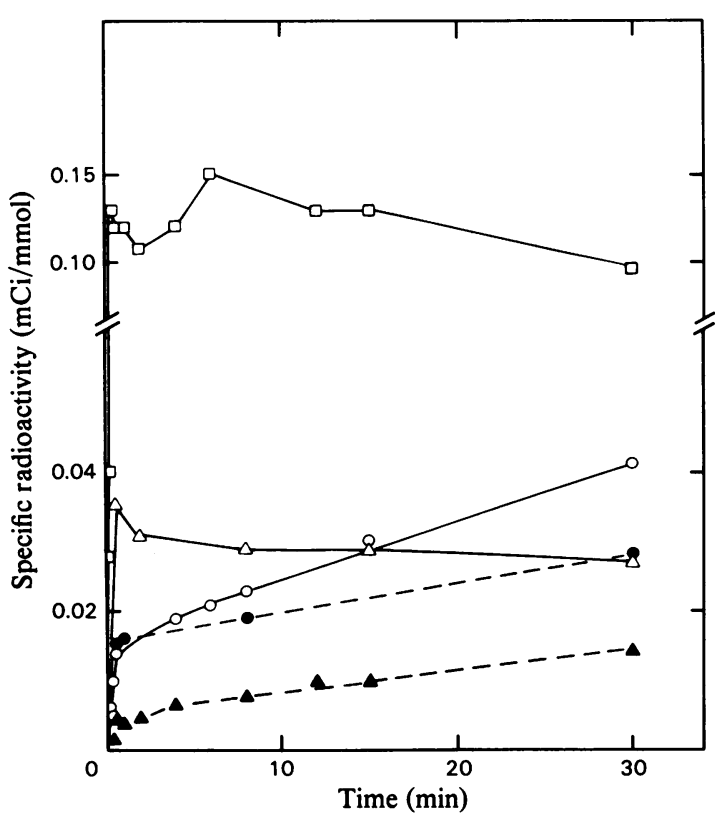

Fig. 3. Incorporation of $\left[{ }^{14} \mathrm{C}\right]$ glutamate into tricarboxylic acid-cycle intermediates

Cells were harvested at the preculmination stage of development, suspended in phosphate buffer $(5 \mathrm{~mm}$, $\mathrm{pH}$ 7.0) and incubated with $\left[{ }^{14} \mathrm{C}\right]$ glutamate. Portions were removed at intervals, frozen and extracted with $75 \%$ ethanol. The extracts were chromatographed on Dowex 50(X12)and AG1-1 (X10) ion-exchange resins. The fractions containing malate $(O), 2$-oxoglutarate $(\square)$, succinate $(\Delta)$, fumarate $(\bullet)$ and citrate $(\Delta)$ were collected, freeze-dried and their specific radioactivities determined.

2-oxoglutarate) remained approximately constant in specific radioactivity over the course of the experiment, whereas others (citrate, fumarate and malate) continued increasing in radioactivity, but at a much lower rate. The 2-oxoglutarate pool, derived from glutamate by transamination or dehydrogenation, showed the highest specific radioactivity. Succinate was labelled to about one-quarter of the specific radioactivity of 2-oxoglutarate, its immediate precursor. Fumarate and malate were labelled initially to about the same specific radioactivity. However, the subsequent rate of labelling was greater for malate. Citrate, initially, was labelled to about onethird the specific radioactivity of malate and fumarate and the subsequent rate of increase was similar to that of fumarate.

The homogeneity of the fractions recovered from column fractionation was investigated by t.l.c. as described in the Methods section. Succinate, fumarate, malate and citrate were found to be radiochemically pure. However, $25 \%$ of the label in the 2-oxoglutarate fraction did not chromatograph as such. In the experiments reported here this problem was circumvented by assaying the fraction for 2-oxoglutarate, which entails its conversion to glutamate, followed by isolation of the resultant glutamate by ion-exchange chromatography. Control assays indicated a $100 \%$ conversion of 2-oxoglutarate to glutamate. The glutamate recovered was then counted for radioactivity. A similar labelling experiment was also performed at the aggregation stage of development and yielded essentially similar results for those metabolites that could be recovered in sufficient radiochemical yield. A decreased permeability of Dictyostelium to exogenous precursors early in differentiation has already been demonstrated (Wright \& Bard, 1963).

It was also shown that, under the experimental conditions used for the labelling studies, the concentrations of those intermediates examined (succinate, fumarate, malate and citrate) exhibited a $10-15 \%$ increase over the first $6-10 \mathrm{~min}$ of incubation and

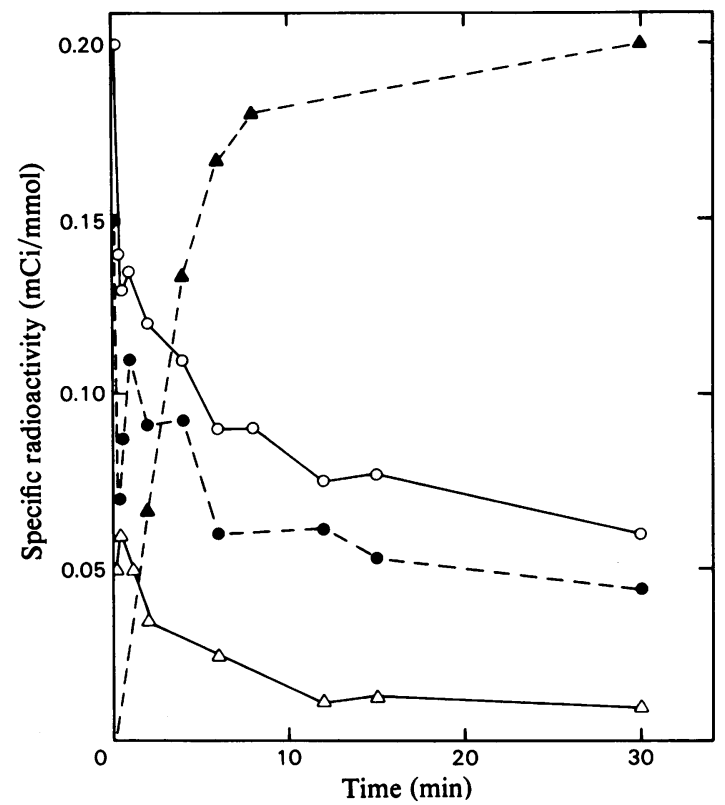

Fig. 4. Incorporation of $\left[{ }^{14} \mathrm{C}\right]$ aspartate into tricarboxylic acid-cycle intermediates

Cells were harvested at the preculmination stage of development, suspended in phosphate buffer $(5 \mathrm{mM}$, pH 7.4) and incubated with $\left[{ }^{14} \mathrm{C}\right]$ aspartate. Portions were removed at intervals, frozen and extracted with $75 \%$ ethanol. The extracts were chromatographed on Dowex AG1-1 (X10)ion-exchange resin. The fractions containing malate $(0)$, succinate $(\Delta)$, fumarate $(\bullet)$ and citrate $(\Delta)$ were collected, freeze-dried and their specific radioactivities determined. 
remained constant thereafter; we assume the system to be in metabolic steady state.

Fig. 4 shows the entry of $\left.{ }^{14} \mathrm{C}\right]$ aspartate into the various tricarboxylic acid-cycle-intermediate pools. Although the metabolic relationship between aspartate and oxaloacetate is superficially similar to that between glutamate and 2-oxoglutarate (large amino acid precursor pool supplying a much smaller product pool), the labelling patterns produced by the two ${ }^{14} \mathrm{C}$-labelled amino acids are very different. The specific radioactivities of three of the intermediates (succinate, fumarate and malate) exhibit a rapid decrease from initially high values, followed by a more gradual decline. No radioactivity could be detected in 2-oxoglutarate. Citrate was labelled rapidly over the first $8 \mathrm{~min}$, and then more slowly.

Fig. 5 shows the incorporation of $\left[{ }^{14} \mathrm{C}\right]$ alanine into various intermediates. Label could not be detected in succinate, fumarate, malate or 2-oxoglutarate. Label was incorporated into acetyl-CoA, citrate and a compound eluted between glutamate and succinate,

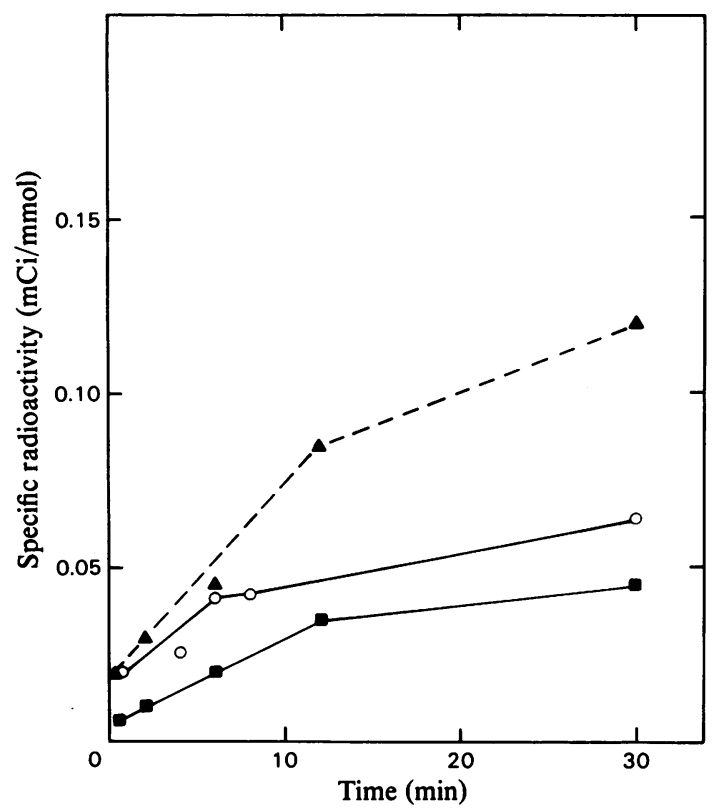

Fig. 5. Incorporation of $\left[{ }^{14} \mathrm{C}\right]$ alanine into tricarboxylic acid-cycle intermediates

Cells were harvested at the preculmination stage of development, suspended in phosphate buffer $(5 \mathrm{~mm}$, pH7.4) and incubated with $\left[{ }^{14} \mathrm{C}\right]$ alanine. Portions were removed at intervals, frozen and extracted with $75 \%$ ethanol. The extracts were chromatographed on Dowex AG1-1 (X10)ion-exchange resin. The fractions containing citrate $(\Delta)$, acetyl-CoA $(0)$ and lactate $(\square)$ were collected, freeze-dried and their specific radioactivities determined. which proved to be lactate. Citrate showed the highest specific radioactivity, followed by acetyl-CoA and lactate.

\section{Discussion}

\section{Interpretation of glutamate labelling}

The labelling pattern obtained with $\left[{ }^{14} \mathrm{C}\right]$ glutamate is susceptible to several interpretations. First, $\left[{ }^{14} \mathrm{C}\right]-$ glutamate equilibrates immediately with the cellular glutamate pool, the 2-oxoglutarate pool and the tricarboxylic acid-cycle intermediates (see Scheme 1). This is consistent with both the immediate conversion of $10 \%$ of the added label to tricarboxylic acid-cycle intermediates and the rapid initial rise $(<30 \mathrm{~s})$ in the specific radioactivity of all the intermediates examined. Several intermediates (malate, fumarate and citrate) then exchange with cytoplasmic pools. This would account for the slower subsequent rise in specific radioactivity observed for the above intermediates. 2-Oxoglutarate and succinate remain constant in specific radioactivity. This may be because the cytoplasmic pool has already been labelled in $30 \mathrm{~s}$ or because no exchange occurs. Thus the rapid initial rise in specific radioactivity shown by all the intermediates would represent the labelling of intramitochondrial metabolite pools active in cycling, and the subsequent lower rate of increase would represent the labelling of cytoplasmic pools due to a mitochondrial/cytoplasmic metabolite exchange.

There are several possibilities for the route of entry of label into the 2-oxoglutarate pool. Glutamate may be converted to 2-oxoglutarate by transamination or oxidative deamination. Glutamate is the usual transamination product from other amino acids, through the action of glutamate transaminase. In many systems the enzyme is found in both mitochondrial and cytoplasmic compartments. Oxidative deamination of glutamate also results in the formation of 2-oxoglutarate. This deaminase has been isolated from Dictyostelium and shown to exist in two forms, one in each compartment (Langridge et al., 1977).

A second interpretation of the $\left[{ }^{14} \mathrm{C}\right]$ glutamate labelling profile is based on possible biochemical differences between the two presumptive cell types that exist at preculmination, e.g. differential permeability to glutamate, differential cycle activity (Farnsworth \& Loomis, 1974; Takeuchi, 1960) or a metabolite exchange between the cell types. Therefore a $\left[{ }^{14} \mathrm{C}\right]$ glutamate-labelling experiment was performed with cells harvested at the late aggregation stage of development. The metabolites isolated from these aggregation-stage cells exhibited a similar labelling pattern. Differentiation into the two cell types has not occurred at this stage of development. 


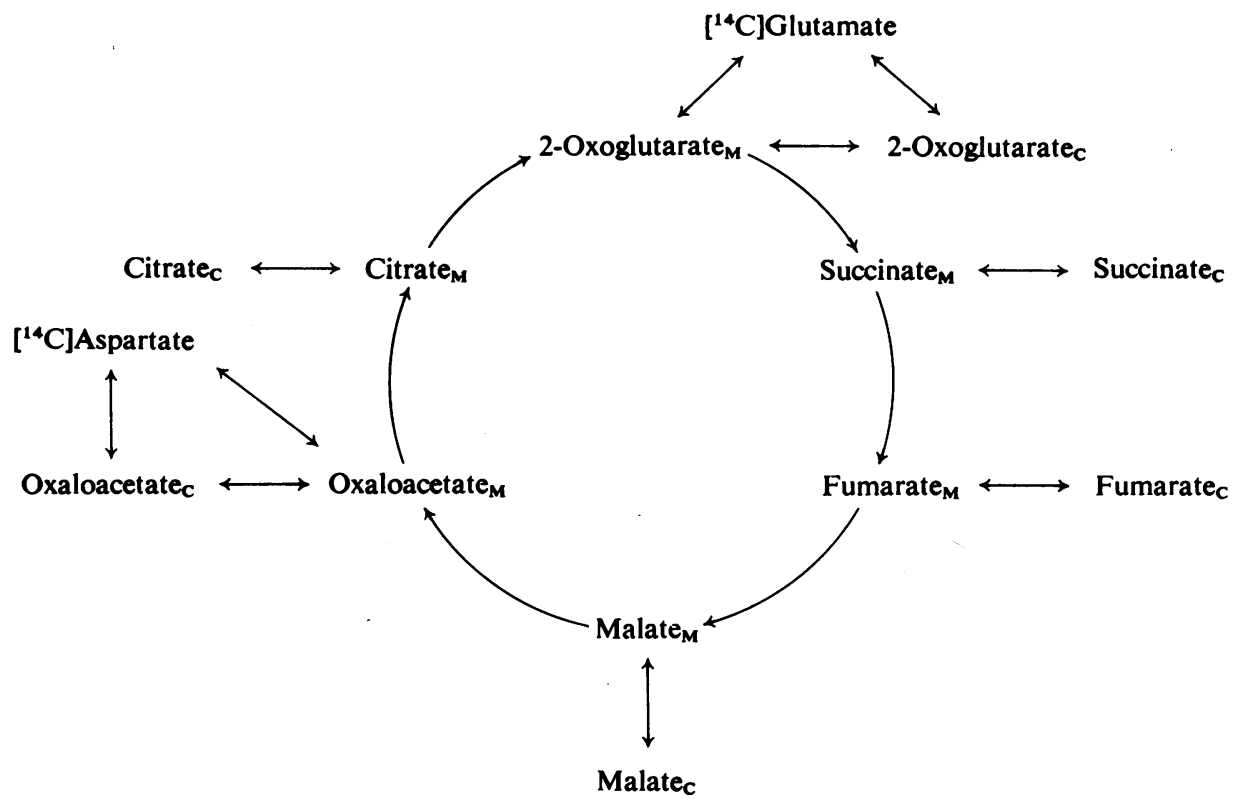

Scheme 1. Tricarboxylic acid cycle

Cycle and non-cycle metabolite pools are designated $\mathrm{M}$ and $\mathrm{C}$ respectively.

\section{Interpretation of aspartate labelling}

It was initially thought that the pattern of labelling observed with $\left[{ }^{14} \mathrm{C}\right]$ aspartate might reflect a cytoplasmic metabolism of aspartate. However, this would require the presence in the cytoplasm of both succinate dehydrogenase and citrate synthase, which are normally mitochondrial enzymes. Glyoxylatecycle activity might account for the citrate-labelling pattern, with label entering citrate from $\left[{ }^{14} \mathrm{C}\right]$ oxaloacetate formed through the action of aspartate aminotransferase on $\left[{ }^{14} \mathrm{C}\right]$ aspartate. However, a cycle of this nature would also label succinate and malate and the labelling of these other intermediates ought to follow the labelling pattern of citrate. In addition, Parish (1975) failed to detect malate synthase or isocitrate lyase, two enzymes distinctive to the glyoxylate cycle, in Dictyostelium.

The labelling pattern obtained can be explained as follows. Aspartate is transaminated to oxaloacetate either in the cytoplasm or the mitochondrion. The mitochondrial pool of oxaloacetate and hence citrate becomes labelled. Citrate is converted to aconitate, isocitrate and 2-oxoglutarate. We would expect then to isolate 2-oxo[ $\left[{ }^{14} \mathrm{C}\right]$ glutarate. There are probably two reasons why we do not. (a) A high exchange rate for the glutamate $\leftrightarrow 2$-oxoglutarate reaction has been reported in other systems (Balázs \& Haslam, 1965). Since the glutamate pool is much larger than the 2oxoglutarate pool, this exchange would reduce the specific radioactivity of the latter. In addition, $(b)$ the 2-oxoglutarate pool isolated is a mixture of both intraand extra-mitochondrial pools. This would reduce the specific radioactivity of the isolated 2-oxoglutarate, since a large part of the 2-oxoglutarate pool may be extramitochondrial.

The labelling patterns of malate, fumarate and succinate can be accounted for by a reversal of the malate dehydrogenase, fumarase and succinate dehydrogenase reactions. These reactions are all reversible (Lowenstein, 1967). The oxaloacetate pool (not measurable) from which malate is synthesized, and presumably the aspartate pool associated with it, must be turning over rapidly to result in the rapid decline in specific radioactivity that is observed for malate.

If the cycle flux is $0.4 \mathrm{~mm} / \mathrm{min}$ (Kelly et al., 1979) and the total citrate pool is $0.06 \mathrm{~mm}$, calculations indicate that this pool should label more rapidly than observed (about $6 \mathrm{~min}$ ). There are several possible explanations: (1) the oxaloacetate pool from which citrate is synthesized may be distinct from that which is used for malate synthesis and may take longer to equilibrate with the $\left[{ }^{14} \mathrm{C}\right]$ aspartate pool; or (2) the enzymes converting 2-oxoglutarate to citrate may be physically associated in the cell in such a way that the intermediates produced by one enzyme in the complex serve as substrate for the next. It has already been shown that such an association could exist for citrate synthase and malate dehydrogenase (Harper \& Srere, 1977; Koch-Schmidt et al., 1977). Thus $\left[{ }^{14} \mathrm{C}\right]$ aspar- 
tate or its transamination product $\left[{ }^{14} \mathrm{C}\right]$ oxaloacetate appear to be compartmentalized. In the first compartment malate, fumarate and succinate are labelled by a reversal of the cycle reactions, and in the other citrate is labelled more slowly. In contrast, $\left[{ }^{14} \mathrm{C}\right]-$ glutamate equilibrates with a stable cellular pool and 2 -oxo $\left[{ }^{14} \mathrm{C}\right]$ glutarate derived from it gains immediate access to the cycle. Thus the metabolism of $\left[{ }^{14} \mathrm{C}\right]$ glutamate and $\left[{ }^{14} \mathrm{C}\right]$ aspartate differs.

\section{Interpretation of alanine labelling}

Alanine is transaminated to pyruvate from which acetyl-CoA, citrate and lactate are all derived. These last three are the only intermediates in which label was detected. Lactate dehydrogenase is present during growth and differentiation in Dictyostelium (Firtel \& Brackenbury, 1972). Though citrate synthesis is probably mitochondrial, the other cycle intermediates fail to show any incorporation. In addition, the production of ${ }^{14} \mathrm{CO}_{2}$ from [U- ${ }^{14} \mathrm{C}$ ]alanine (Fig. 1) is low. If the high rate of exchange for the glutamate $\rightleftharpoons 2$ oxoglutarate reaction, invoked earlier in the interpretation of the $\left[{ }^{14} \mathrm{C}\right]$ aspartate data [and discussed more fully in the following paper (Kelly et al., 1979)] is correct, then the lack of incorporation of label into cycle-intermediate pools other than citrate can be explained. Since the acetyl-CoA formed from $\left[{ }^{14} \mathrm{C}\right]-$ alanine and used in citrate synthesis is not released on the first turn of the cycle, and since the above-mentioned exchange reaction would lower its specific radioactivity in 2-oxoglutarate, the low rate of ${ }^{14} \mathrm{CO}_{2}$ production from $\left[{ }^{14} \mathrm{C}\right]$ alanine is also explained.

This work was supported by U.S. Public Health Service grant nos. AG00A33 and AG00260 from the National Institutes of Health and by a U.S. Public Health Service post-doctoral fellowship no. AG05065 to J. K. K.

\section{References}

Ashworth, J. M., Duncan, D. \& Rowe, A. J. (1969) Exp. Cell Res. 58, 73-78

Balázs, R. \& Haslam, R. J. (1965) Biochem. J. 94, 131-141

Barravechio, J., Baumann, P. \& Wright, B. E. (1969) Appl. Microbiol. 17, 641-642

Bergmeyer, H. U.(ed.)(1976) Methods in Enzymatic Analysis, Academic Press, New York
Brühmüller, M. \& Wright, B. E. (1963) Biochim. Biophys. Acta 71, 50-57

Cleland, S. V. \& Coe, E. L. (1964) Biochim. Biophys. Acta 192, 446-454

Erikson, S. K. \& Ashworth, J. M. (1969) Biochem. J. 113, 567-568

Farnsworth, P. \& Loomis, W. F., Jr. (1974) Dev. Biol. 41, 77-83

Firtel, R. A. \& Brackenbury, R. W. (1972) Dev. Biol. 27, 307-321

George, R. P., Hohl, H. R. \& Raper, K. B. (1972) J. Gen. Microbiol. 70, 477-489

Gregg, J. H. (1950) J. Exp. Zool. 114, 173-196

Gustafson, G. L. \& Thon, L. A. (1979) Fed. Proc. Fed. Am. Soc. Exp. Biol. 38, 465

Harper, L. \& Srere, P. A. (1977) Arch. Biochem. Biophys. 184, 529-534

Kelly, P. J., Kelleher, J. K. \& Wright, B. E. (1979) Biochem. J. 184, 589-597

Koch-Schmidt, A. C., Matiasson, B. \& Mosbach, K. (1977) Eur. J. Biochem. 81, 71-78

Langridge, W. H. R., Komuniecki, P. \& DeToma, F. J. (1977) Arch. Biochem. Biophys. 178, 581-587

Liddell, G. \& Wright, B. E. (1961) Dev. Biol. 3, 265-276

Lloyd, J. (1970) The Mitochondria of Micro-organisms, Academic Press, New York

Lowenstein, J. M. (1967) Metab. Pathways 3rd Ed. 1, 147-254

Marshall, R., Sargent, D. \& Wright, B. E. (1970) Biochem. 9, 2087-2094

Parish, R. W. (1975) Eur. J. Biochem. 58, 523-531

Pong, S. S. \& Loomis, W. F., Jr. (1971a) J. Biol. Chem. 246, $4412-4416$

Pong, S. S. \& Loomis, W. F., Jr. (1971b) J. Biol. Chem. 246, 4867-4873

Porter, J. S. \& Wright, B. E.(1977) Arch. Biochem. Biophys. 181, 155-163

Schoner, W. \& Seubert, W. (1974) in Methods in Enzymatic Analysis (Bergmeyer, H. U., ed.), pp. 1994-2000, Academic Press, New York

Sussman, M. \& Sussman, R. (1969) Symp. Soc. Gen. Microbiol. 19, 403-435

Takeuchi, I. (1960) Dev. Biol. 2, 343-366

Weiner, E. \& Ashworth, J. M. (1970) Biochem. J. 118, 505-512

White, G. J. \& Sussman, M. (1961) Biochim. Biophys. Acta 53, 285-293

Wright, B. E. (1964) Biochem. Physiol. Protozoa 3, 341-381

Wright, B. E. (1967) Arch. Mikrobiol. 59, 335-344

Wright B. E. \& Anderson, M. L. (1960) Biochim. Biophys. Acta 43, 62-66

Wright, B. E. \& Bard, S. (1963) Biochim. Biophys. Acta 71, 45-49 